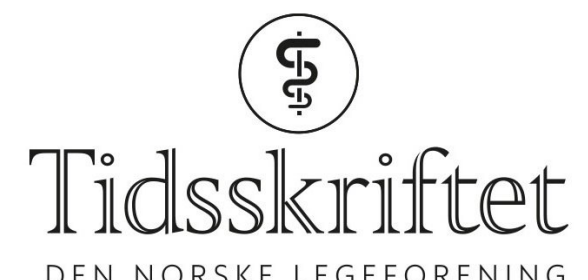

\title{
Langtidsoppfølging etter atrieflimmeroperasjon og samtidig åpen hjertekirurgi
}

ORIGINALARTIKKEL

KNUT SVERRE ANDERSEN

E-post: knutsverre@me.com

Thoraxkirurgisk seksjon

Hjerteavdelingen

Haukeland universitetssjukehus

Han har bidratt med idé, utforming/design av studien, datainnsamling, analyse og tolking av data, litteraturs $\emptyset \mathrm{k}$, utarbeiding/revisjon av manuset samt godkjenning av innsendte manusversjon. Knut Sverre Andersen er dr.med., spesialist i thoraxkirurgi og pensjonert overlege.

Forfatteren har fylt ut ICMJE-skjemaet og oppgir følgende interessekonflikter: Den norske delen av CURE-AF-studien er sponset av Medtronic.

\section{KETIL GRONG}

Klinisk institutt 2

Universitetet i Bergen

Han har bidratt med utforming/design, analyse og tolking av data, litteratursøk, utarbeiding/revisjon av manuset samt godkjenning av innsendte manusversjon.

Ketil Grong er dr.med. og professor.

Forfatteren har fylt ut ICMJE-skjemaet og oppgir ingen interessekonflikter.

\section{PER-IVAR HOFF}

Hjerteavdelingen

Haukeland universitetssjukehus

Han har bidratt med analyse og tolkning av EKG-data samt godkjenning av innsendte manusversjon. Per-Ivar Hoff er spesialist i kardiologi og pensjonert overlege ved Hjertearytmisenteret. Forfatteren har fylt ut ICMJE-skjemaet og oppgir ingen interessekonflikter.

\section{ALEXANDER WAHBA}

Klinikk for thoraxkirurgi

St. Olavs hospital

og

Institutt for sirkulasjon og bildediagnostikk

NTNU

Han har bidratt med utforming/design av studien, tolking av data samt godkjenning av innsendte manusversjon.

Alexander Wahba er dr.med., overlege og professor.

Forfatteren har fylt ut ICMJE-skjemaet og oppgir følgende interessekonflikter: Den norske delen av CURE-AF-studien er sponset av Medtronic. 


\section{BAKGRUNN}

Pasienter med atrieflimmer/flutter som skal gjennomgå en åpen hjerteoperasjon, kan behandles med ablasjon av arytmogene foci under samme inngrep. Sinusrytmen gjenopprettes hos de fleste på kort sikt, men langtidsresultatene er mer usikre. I denne studien, som er en del av den internasjonale CURE-AF-studien, evalueres resultater etter Cox-maze IV-operasjon for atrieflimmer i Norge ved oppfølging etter seks år.

\section{MATERIALE OG METODE}

19 pasienter inngikk i denne prospektive kohortstudien. Atrieflimmer hadde vart i 40 måneder i gruppen med langvarig persisterende atrieflimmer $(n=12) \operatorname{og} 6$ måneder i gruppen med persisterende atrieflimmer $(\mathrm{n}=7)$. Operasjon for atrieflimmer ble utført etter Cox-maze IV-prosedyren i CURE-AF-protokollen. De første 12 månedene var oppfølgingen strikt etter CURE-AF-protokoll, deretter var oppfølgingen i primærhelsetjenesten.

\section{RESULTATER}

Sinusrytme var reetablert hos 11 pasienter ved utskrivning og hos 14 pasienter seks måneder postoperativt. Ved oppfølging etter 5-6 år hadde alle pasienter med langvarig persisterende atrieflimmer fått residiv. To av disse fikk sinusrytme etter elektrokonvertering. Seks av syv i gruppen med persisterende atrieflimmer hadde sinusrytme etter 5-6 år.

\section{FORTOLKNING}

Initialt var resultatene gode, med retablering av sinusrytme hos over av pasientene etter 6-9 måneder. Fem år senere ble det påvist høy residivfrekvens hos pasienter med langvarig persisterende atrieflimmer. Flere residiv var ikke blitt oppdaget eller forsøkt behandlet av helsevesenet. $2 / 3$ av pasientene etter 6-9 måneder. Fem år senere ble det påvist høy residivfrekvens hos pasienter med langvarig persisterende atrieflimmer. Flere residiv var ikke blitt oppdaget eller forsøkt behandlet av helsevesenet.

Blant pasienter som skal gjennomgå et hjertekirurgisk inngrep, er forekomsten av atrieflimmer høy (1). Moderne metoder for kirurgisk ablasjonsbehandling, som Cox-maze (labyrint) IV (CMIV), har gjort det enklere å kombinere kirurgisk behandling av atrieflimmer med annen hjertekirurgi (2). Behandlingen kan nå gjennomføres mye raskere og sikrere enn før da atrievevet måtte deles med saks og kniv før det ble sydd sammen igjen. På kort sikt (ett år) er det rapportert om en suksessrate på 89 \% etter CMIV-prosedyre (2). På lengre sikt er slik ablasjon forbundet med redusert hyppighet av postoperativ atrieflimmer, slag og hjertesvikt (3) samt bedret langtidsoverlevelse (4).

Multisenterstudien Concomitant Utilization of Radio Frequency Energy for Atrial Fibrillation (CURE-AF) ble utført i USA i perioden 2007-11 for å dokumentere effekt og sikkerhet av irrigert uni- og bipolar radiofrekvensablasjon ved behandling av atrieflimmer etter CMIV-protokoll under samtidig åpen hjerteoperasjon. Etter 6-9 måneder viste resultatene at $66 \%$ av totalt 150 pasienter var uten atriale takyarytmier (5).

Kirurgisk ablasjonsbehandling av atrieflimmer regnes nå som en klasse I-anbefaling for utvalgte pasienter (1). Det er derfor viktig å ta stilling til om pasienter med atrieflimmer skal tilbys kirurgisk ablasjon i forbindelse med planlagt hjerteoperasjon. I denne artikkelen presenteres kort- og langtidsresultater for pasientene som deltok i den norske delen av CURE-AF-studien.

\section{Materiale og metode}

\section{INKLUSJON OG TIDLIG OPPFØLGING}

To norske hjertekirurgiske sentre deltok i CURE-AF-studien i perioden 2008-10.19 pasienter 
(ti i Trondheim og ni i Bergen) ble inkludert, operert og fulgt opp etter CURE-AF-protokoll av samme hjertekirurg ved hvert senter. Data fra den norske delen av studien ble ikke tatt med i rapporten fra Damiano og medarbeidere (5). Både den primære CURE-AF-studien i Norge (European Companion Protocol to the US CURE-AF study, IDE Go6o22o/S4 Permanent AF Rev E og IDE Go70046/S1 Persistent AF Rev B) og den senere langtidsoppfølgingen ble vurdert som kvalitetssikringsprosjekter av Regional komité for medisinsk og helsefaglig forskningsetikk (REK) Vest (067.08 og 2015/257). CURE-AF-studien ble registrert i 2007 (NCTo0431834). Den europeiske armen av studien ble etterregistrert 27.11.2020 i ClinicalTrials.gov (NCTo4645615).

Pasienter planlagt for elektiv hjertekirurgi på vanlige indikasjoner og som i tillegg hadde atrieflimmer og oppfylte inklusjonskriteriene i CURE-AF-studien, ble fortløpende inkludert. Venstre ventrikkel-funksjon og venstre atriums diameter ble målt med transtorakal ekkokardiografi av kardiolog. Pasientene ble grundig informert om risiko og fordeler forbundet med deltakelse i studien, og de undertegnet samtykkeerklæring.

Ablasjonene ble utført med bipolart utstyr (Cardioblate LP, Medtronic, Minneapolis, MN, USA) og/eller unipolart utstyr (Cardioblate Monopolar Pen, Medtronic) forbundet med en radiofrekvensgenerator (Cardioblate 68000 RF Generator, Medtronic). Under ablasjon ble vevet kjølt ned med saltvannsinfusjon. Ablasjonslinjene er skjematisk visualisert i figur 1 og figur 2. Alle pasientene fikk anlagt fullt sett av ablasjonslinjer uavhengig av type atrieflimmer og hovedinngrep. Bipolart utstyr ble brukt til lungeveneablasjon og linjen mellom øvre og nedre hulvene. De andre linjene ble generert med kombinasjoner av unipolart og bipolart utstyr. Lungeveneablasjon ble utført på bankende hjerte (før kardioplegi). Primært ledningsblokk mellom lungevener og venstre atrium ble oppnådd hos 16 pasienter, mens tre trengte flere ablasjoner for å oppnå blokk. I tillegg ble venstre aurikkel amputert $(n=9)$ eller ligert/lukket med $\operatorname{sutur}(n=8)$ eller suturmaskin $(n=2)$.

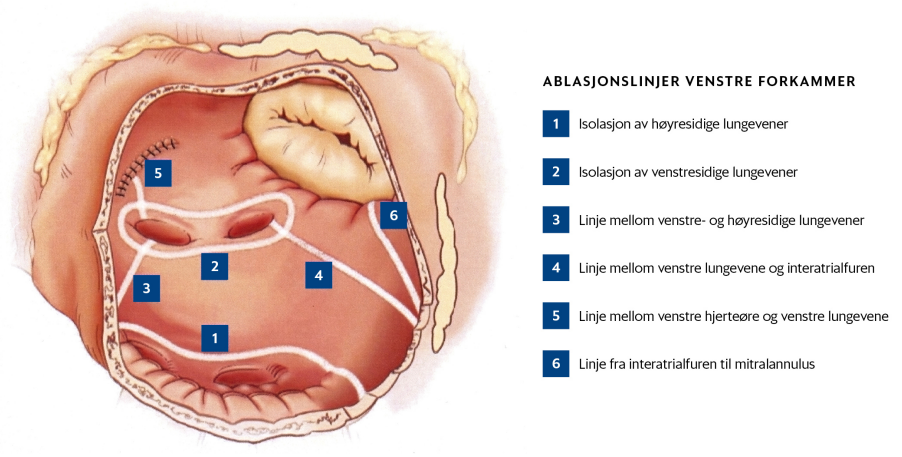

Figur 1 Ablasjonslinjer etter CURE-AF-protokollen generert med radiofrekvensablasjon. Figur er gjengitt etter tillatelse fra Medtronic.

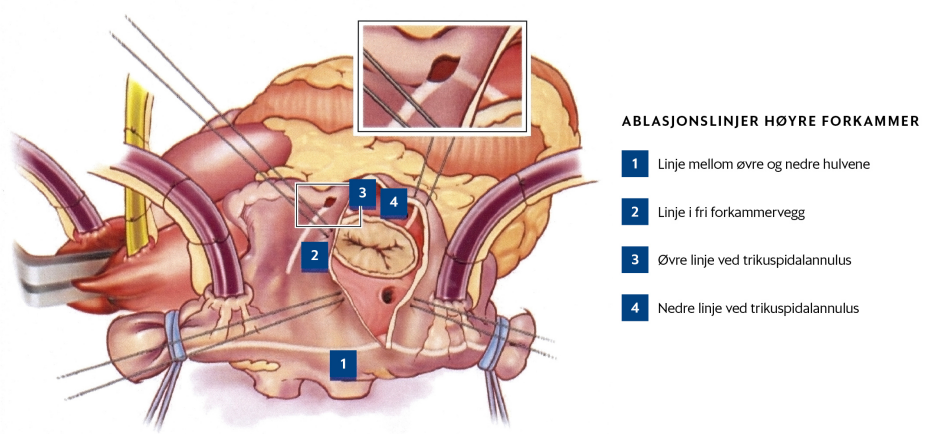

Figur 2 Ablasjonslinjer etter CURE-AF-protokollen generert med radiofrekvensablasjon. Figur er gjengitt etter tillatelse fra Medtronic.

Medikasjon med amiodaron ble påbegynt innen få dager postoperativt og kontinuert (200 mg daglig) i tre måneder. 18 av 19 pasienter brukte warfarin allerede før operasjonen. Warfarin skulle etter CURE-AF-protokollen brukes i minst seks måneder etter inngrepet. 
Det viste seg imidlertid at warfarin ble kontinuert på klinisk indikasjon hos $17 \mathrm{av}$ 18 pasienter til studiens avslutning.

Betegnelsen permanent atrieflimmer bør ikke brukes for pasienter som får utført kirurgisk ablasjon (6). I denne studien vil resultatene bli presentert samlet for hele gruppen og separat for de to undergruppene persisterende atrieflimmer (varighet $>7$ dager eller behov for elektrokonvertering) og langvarig persisterende atrieflimmer (varighet $>12$ måneder) der dette er relevant. Endepunkt for rytmestatus i CURE-AF-studien, dokumentert med 24 timers Holter-registrering, var seks måneder ved langvarig persisterende atrieflimmer og ni måneder ved persisterende atrieflimmer. På disse tidspunktene var klasse I- og klasse IIIantiarytmika seponert. Deretter ble oppfølgingen gradvis overlatt til fastleger og poliklinikker.

\section{LANGTIDSOPPFØLGING}

Én pasient døde noen måneder etter operasjonen, mens de gjenværende 18 ble fulgt opp 5-6 år etter operasjonen med klinisk undersøkelse, nøyaktig anamnese for hjerterytme og 12avledningers EKG. Journalopplysninger, inkludert alle EKG-registreringer, ble innhentet fra fastleger, kardiologer og lokalsykehus.

I tiden etter Holter-registreringen (6-9 måneder postoperativt) fikk to pasienter i gruppen med persisterende atrieflimmer utført kateterablasjon henholdsvis 11 måneder og 65 måneder etter operasjonen. De beholdt sinusrytme etter det. To pasienter i gruppen med langvarig persisterende atrieflimmer fikk implantert permanent pacemaker.

Under etterunders $ø$ kelsen kom det fram at noen pasienter allerede hadde utviklet kronisk atrieflimmer, mens det hos andre ble funnet holdepunkter for residiv som trengte videre diagnostikk og behandling. Dette ble iverksatt i løpet av høsten/vinteren 2015. Endelig rytmestatus ble gjort opp i desember 2015.

\section{STATISTIKK}

Data er presentert som middelverdier \pm standardavvik for normaldistribuerte data, ellers som median (1. kvartil og 3. kvartil). Toprøve-t-test og Mann-Whitney U-test for kontinuerlige variabler og Fishers eksakte test for nominale data ble anvendt for å sammenlikne data mellom gruppene med langvarig persisterende atrieflimmer og persisterende atrieflimmer.

\section{Resultater}

Preoperative data er samlet i tabell 1. Med unntak av median varighet av atrieflimmer, som var lenger i gruppen med langvarig persisterende atrieflimmer sammenliknet med persisterende atrieflimmer (40 versus 6 måneder), var det ingen statistisk signifikante forskjeller mellom de to gruppene. Median alder var 72 år, og flertallet av pasientene var i NYHA (New York Heart Association)-klasse II (milde symptomer). Venstre ventrikkelfunksjonen var normal. Forekomsten av koronarsykdom var lik i begge grupper. Nesten alle (18/19) hadde fått antikoagulasjonsbehandling med warfarin, og 13 ble behandlet med betablokkere.

\section{Tabell 1}

Preoperative karakteristika for en gruppe pasienter $(\mathrm{n}=19)$ som fikk utført kirurgisk ablasjon for atrieflimmer i forbindelse med åpen hjertekirurgi i Bergen eller Trondheim 2008-10. Antall dersom annet ikke er angitt.

\begin{tabular}{|lr|}
\hline Variabel & Data \\
\hline Alder (år), median (1. kvartil; 3. kvartil) & $72(68 ; 73)$ \\
\hline
\end{tabular}




\begin{tabular}{|c|c|}
\hline Variabel & Data \\
\hline Kjønn (antall menn/kvinner) & $15 / 4$ \\
\hline Hypertensjon & 3 \\
\hline Varighet atrieflimmer (måneder), median (1. kvartil; 3. kvartil) & $20(9 ; 53)$ \\
\hline Betablokker & 13 \\
\hline Warfarin & 18 \\
\hline \multicolumn{2}{|l|}{ NYHA'-klasse, antall pasienter } \\
\hline Klasse I & 1 \\
\hline Klasse II & 12 \\
\hline Klasse III & 6 \\
\hline Venstre ventrikkel-ejeksjonsfraksjon (prosent), middelverdi \pm SD & $62 \pm 5$ \\
\hline Diameter venstre atrium $(\mathrm{mm})$, middelverdi $\pm \mathrm{SD}$ & $53 \pm 8$ \\
\hline \multicolumn{2}{|l|}{ Kirurgiske tilstander ${ }^{2}$} \\
\hline Mitralinsuffisiens & 10 \\
\hline Koronarsykdom & 9 \\
\hline Aortaklaffstenose & 3 \\
\hline
\end{tabular}

${ }^{1}$ New York Heart Association

${ }^{2}$ Noen pasienter hadde flere tilstander som trengte operativ behandling

Hovedinngrepene var mitraloperasjon $(n=10)$, aortokoronar bypassoperasjon $(n=6)$ og aortaklaffprotese $(n=3)$ (tabell 2 ). Mitralplastikk ble signifikant hyppigere $(\mathrm{p}=0,01)$ utført i gruppen med persisterende atrieflimmer. Venstre arteria mammaria interna ble brukt som bypass hos åtte av ni koronaropererte. I gruppen med langvarig persisterende atrieflimmer fikk fem pasienter også utført sekundære operative prosedyrer (lukning av foramen ovale, reseksjon av aneurisme i aorta ascendens, trikuspidalplastikk). Median ablasjonstid var 379 sekunder. Det var ingen forskjell i ablasjonstid mellom gruppene, men betydelig variasjon mellom individuelle pasienter. Peri- og postoperative komplikasjoner forekom hos syv pasienter (37\%), ingen klart relaterte til CMIV-prosedyren. Median liggetid i sykehus var åtte dager, og det var ingen mortalitet innen zo dager.

\section{Tabell 2}

Per- og postoperative data for en gruppe pasienter $(\mathrm{n}=19)$ som fikk utført kirurgisk ablasjon for atrieflimmer i forbindelse med åpen hjertekirurgi i Bergen eller Trondheim 2008-10. Antall dersom annet ikke er angitt.

\begin{tabular}{|c|c|}
\hline Variabel & Data \\
\hline \multicolumn{2}{|l|}{ Hovedinngrep } \\
\hline Mitraloperasjon, totalt & 10 \\
\hline Plastikk/ring & 6 \\
\hline Protese & 4 \\
\hline Aortaklaffprotese & 3 \\
\hline Koronar bypassoperasjon $^{1}$ & 6 \\
\hline Kardiopulmonal bypass tid $(\mathrm{min})$, middelverdi \pm SD & $192 \pm 71$ \\
\hline Aortaavklemming $(\mathrm{min})$, middelverdi $\pm \mathrm{SD}$ & $129 \pm 65$ \\
\hline Total radiofrekvensablasjonstid (sek), median (1. kvartil; 3. kvartil) & $379(325 ; 552)$ \\
\hline Sykehusopphold (dager), median (1. kvartil; 3. kvartil) & $8(5 ; 9)$ \\
\hline
\end{tabular}

${ }^{1}$ Koronar bypassoperasjon ble utført hos i alt ni pasienter, tre av disse var ledd i en kombinert prosedyre

Ved utskrivning hadde $58 \%(11 / 19)$ sinusrytme, 5 av 7 i gruppen med persisterende atrieflimmer og 6 av 12 i gruppen med langvarig persisterende atrieflimmer $(\mathrm{p}=0,63)$ (figur 3 a). I løpet av de påfølgende 6-9 månedene ble 14 av 19 pasienter (74\%) elektrokonvertert på grunn av vedvarende eller residiverende supraventrikulære takykardier (SVT). 


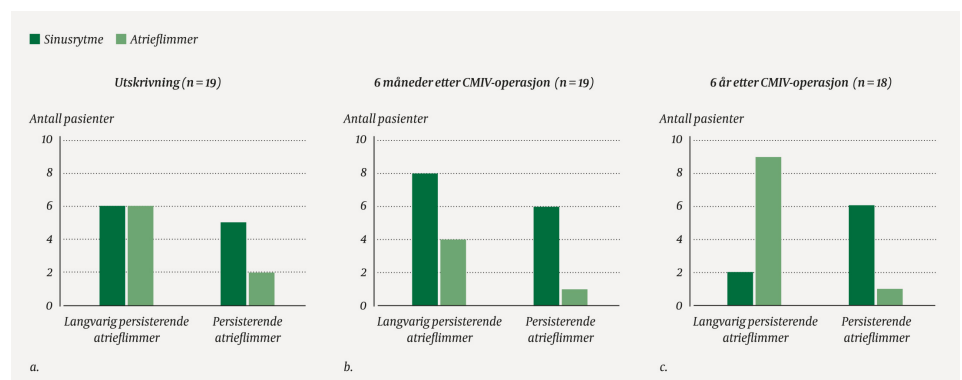

Figur 3 Forekomst av sinusrytme og atrieflimmer etter radiofrekvensablasjon for atrieflimmer etter CURE-AF-protokollen ved utskrivning ( $a$ ), etter seks måneder (b) og etter seks år (c).

Seks måneder etter operasjonen (figur 3b) hadde 14/19 pasienter (74\%) sinusrytme, 8 av 12 i gruppen med langvarig persisterende atrieflimmer og 6 av 7 i gruppen med persisterende atrieflimmer $(\mathrm{p}=\mathrm{o}, 60)$.

\section{LANGTIDSOPPFØLGING}

Da pasientene ble etterundersøkt etter fem år, viste det seg at 12 av 18 hadde atrieflimmer. 9 av disse 12 hadde hatt sinusrytme etter seks måneder, mens tre hadde atrieflimmer også etter seks måneder. Sinusrytme forelå hos seks pasienter, alle i gruppen med persisterende atrieflimmer.

Syv pasienter med residiv ble vurdert til å trenge videre arytmidiagnostikk og eventuelt elektrokonvertering. Under observasjonsperioden høsten 2015 viste det seg at fire av disse syv hadde paroksysmalt atrieflimmer. Hos to pasienter i gruppen med langvarig persisterende atrieflimmer ble det oppdaget atrieflutter med 2: 1-overledning, som ble vellykket elektrokonvertert. Disse to beholdt sinusrytme til undersøkelsens avslutning. Én pasient ble henvist til elektrokonvertering, men kardiolog fant ikke indikasjon for dette.

Endelig resultat for hele gruppen (figur 3c) var reetablert sinusrytme hos $44 \%$ (8/18), med signifikant forskjell $(p=0,013)$ mellom gruppen med persisterende atrieflimmer $(6 / 7)$ og langvarig persisterende atrieflimmer (2/11).

\section{Diskusjon}

Nesten en tredjedel av pasientene med operasjonstrengende hjertesykdom får påvist atrieflimmer i løpet av de siste tre årene før kirurgi (1). Kirurgisk behandling av atrieflimmer under samtidig hjerteoperasjon er i dag en klasse I-anbefaling for symptomatiske pasienter, både med kort og lang varighet av atrieflimmer (6). Kardiologer og hjertekirurger bør derfor ta stilling til om ablasjonsbehandling skal gjennomføres under samtidig hjerteoperasjon.

Vår studie støtter at radiofrekvensablasjon for atrieflimmer etter CMIV-protokoll er en trygg prosedyre med lite komplikasjoner. På kort sikt og med oppfølging etter fast kontrollregime kan prosedyren forventes å gjenopprette sinusrytme hos mer enn $2 / 3$ av pasientene. Funnene harmonerer med resultatene i CURE-AF-studien publisert av Damiano og medarbeidere (5). De fant at antall pasienter med sinusrytme (uten supraventrikulære takykardier) ved Holter-registrering etter 6-9 måneder (våre tall i parentes) var 66 \% (74\%) for hele gruppen, $63 \%$ (67\%) for gruppen med langvarig persisterende atrieflimmer og $82 \%$ (86\%) for gruppen med persisterende atrieflimmer. Pasientgruppen som er studert og fulgt opp i denne studien, er liten, og vi hadde ingen kontrollgruppe som verifiserer nytten av inngrepet. Pasientene er imidlertid nøyaktig fulgt opp over lang tid etter operasjonen. Gjennomføringen av studien og etterundersøkelsen ligger en del tilbake i tid, men verken indikasjoner, operasjonsmetode eller oppfølgingen av pasienter som har fått kirurgisk ablasjon, har forandret seg vesentlig. Resultatene betraktes derfor fortsatt som relevante.

$\emptyset \mathrm{kt}$ diameter av venstre atrium, kort ablasjonstid og antall tilleggsprosedyrer er vist å øke risikoen for residiv av atrieflimmer (5). Vi kunne ikke påvise slike sammenhenger, antagelig på grunn av seleksjonskriteriene til studien og det lave antallet pasienter. Et komplett 
ablasjonsmønster med transmurale lesjoner er en forutsetning for et godt resultat ved all ablasjon for atrieflimmer (7). Lungeveneablasjonene ble utført med bipolart utstyr, og transmuralitet ble bekreftet ved opphevet impulsledning mellom lungevener og venstre atrium (exit block). Vi erfarte at det hos en del pasienter var nødvendig med gjentatte ablasjoner for å oppnå opphevet impulsledning. Selv der dette var dokumentert, viste det seg at en pasient fikk residiv etter seks måneder i form av atrieflutter fra en ablatert lungevene. Kort ablasjonstid (<36o sekunder) er vist å være en risikofaktor for residiv (5). Median ablasjonstid i vår studie (379 sekunder) var over dette, men med stor variasjon mellom de enkelte pasientene. Ufullstendig ablasjon kan sannsynligvis forklare noen av residivene i denne studien.

Lang preoperativ varighet av atrieflimmer er en risikofaktor for residiv av atrieflimmer (8), noe som bekreftes i vår studie i form av signifikant forskjellig residivrate mellom gruppene med langvarig persisterende atrieflimmer og persisterende atrieflimmer.

Langtidsresultater etter CMIV-operasjon for atrieflimmer viser betydelig variasjon. CUREAF-studien i USA ble avsluttet etter ni måneder, og oppfølgingsdata er oss bekjent ikke publisert. Vi undersøkte hjerterytme fem år etter operasjonen og påviste en høy residivfrekvens av atrieflimmer, spesielt i gruppen med langvarig persisterende atrieflimmer. Residivene ga ofte lite symptomer og ble ikke alltid fanget opp tidlig nok i primærhelsetjenesten (data ikke vist).

Ved studiens avslutning etter 5-6 år hadde $44 \%$ av våre pasienter sinusrytme. Dette er adskillig lavere enn rapportert i to nyere studier fra USA, der henholdsvis $66 \%$ og $64 \%$ hadde sinusrytme fem år etter tilvarende operasjon $(8,9)$. I begge disse studiene ble pasientene nøye fulgt opp og adekvat behandlet for residiv av atrieflimmer i årene etter operasjonen. Siden tidlige resultater i vår studie var på linje med andre sentre, mistenker vi at en viktig årsak til den høye residivraten, er mangler i oppfølging og elektrokonvertering, spesielt i gruppen med langvarig persisterende atrieflimmer. Dette støttes av en studie fra Danmark, der oppfølgingen også var overlatt til primærhelsetjenesten, og der kun henholdsvis $33 \%$ og $25 \%$ av pasientene var uten supraventrikulære takykardier etter fem og syv år (10).

Residivhyppigheten har vist seg å være betydelig etter 18-36 måneder (9), noe som igjen understreker viktigheten av at langvarig oppfølging og rask intervensjon ved residiv av atrieflimmer skjer ved et spesialisert senter $(9,10)$. Dette kommer klart frem under etterundersøkelsen i vår studie, da over en tredjedel av pasientene (7/18) viste seg å ha behov for ny arytmidiagnostikk. I tillegg hadde en del pasienter med langvarig persisterende atrieflimmer utviklet permanent atrieflimmer allerede i løpet av de første årene etter operasjon.

For å bedre langtidsresultatene etter gjennomgått ablasjon for atrieflimmer i forbindelse med hjertekirurgi synes det rimelig å anbefale et fast kontrollopplegg, for eksempel med årlig EKG og eventuelt 24 timers EKG-måling. Slik kan man tidlig avsløre residiv og få iverksatt behandling.

\section{HOVEDFUNN}

Seks måneder etter operasjon for atrieflimmer med Cox-maze IV-teknikk under samtidig åpen hjerteoperasjon hadde $14 \mathrm{av} 19$ pasienter sinusrytme.

Residivfrekvensen på lengre sikt var høy, spesielt hos pasienter med lang preoperativ varighet av atrieflimmer.

Peri- og postoperative komplikasjoner ble observert hos syv pasienter, men ingen var klart relatert til ablasjonsbehandlingen. 


\section{LITTERATUR:}

1. McCarthy PM, Davidson CJ, Kruse J et al. Prevalence of atrial fibrillation before cardiac surgery and factors associated with concomitant ablation. J Thorac Cardiovasc Surg 2020; 159: 2245-53. [PubMed][CrossRef]

2. Damiano RJ, Schwartz FH, Bailey MS et al. The Cox maze IV procedure: predictors of late recurrence. J Thorac Cardiovasc Surg 2011; 141: 113-21. [PubMed][CrossRef]

3. Dunning J, Nagendran M, Alfieri OR et al. Guideline for the surgical treatment of atrial fibrillation. Eur J Cardiothorac Surg 2013; 44: 777-91. [PubMed][CrossRef]

4. Musharbash FN, Schill MR, Sinn LA et al. Performance of the Cox-maze IV procedure is associated with improved long-term survival in patients with atrial fibrillation undergoing cardiac surgery. J Thorac Cardiovasc Surg 2018; 155: 159-70. [PubMed][CrossRef]

5. Damiano RJ, Badhwar V, Acker MA et al. The CURE-AF trial: a prospective, multicenter trial of irrigated radiofrequency ablation for the treatment of persistent atrial fibrillation during concomitant cardiac surgery. Heart Rhythm 2014; 11:39-45. [PubMed][CrossRef]

6. Calkins H, Hindricks G, Cappato R et al. 2017 HRS/EHRA/ECAS/APHRS/SOLAECE expert consensus statement on catheter and surgical ablation of atrial fibrillation. Heart Rhythm 2017; 14: e275-444. [PubMed][CrossRef]

7. Gaita F, Ebrille E, Scaglione M et al. Very long-term results of surgical and transcatheter ablation of long-standing persistent atrial fibrillation. Ann Thorac Surg 2013; 96:1273-8. [PubMed][CrossRef]

8. Henn MC, Lancaster TS, Miller JR et al. Late outcomes after the Cox maze IV procedure for atrial fibrillation. J Thorac Cardiovasc Surg 2015; 150: 1168-76, 1178.e1-2. [PubMed][CrossRef]

9. Ad N, Holmes SD, Stone LE et al. Rhythm course over 5 years following surgical ablation for atrial fibrillation. Eur J Cardiothorac Surg 2015; 47: 52-8, discussion 58. [PubMed][CrossRef]

10. Engelsgaard CS, Pedersen KB, Riber LP et al. The long-term efficacy of concomitant maze IV surgery in patients with atrial fibrillation. Int J Cardiol Heart Vasc 2018; 19: 20-6. [PubMed][CrossRef]

Publisert: 5. januar 2021. Tidsskr Nor Legeforen. DOI: 10.4045/tidsskr.20.0279

Mottatt 29.5.2020, første revisjon innsendt 27.7.2020, godkjent 26.11.2020.

(C) Tidsskrift for Den norske legeforening 2020. Lastet ned fra tidsskriftet.no 